\title{
Glucose tolerance factor extracted from yeast: oral insulin-mimetic and insulin-potentiating agent: in vivo and in vitro studies
}

\author{
Sarah Weksler-Zangen ${ }^{1}$, Tal Mizrahi ${ }^{2}$, Itamar Raz ${ }^{1}$ and Nitsa Mirsky ${ }^{2 *}$ \\ ${ }^{1}$ The Diabetes Unit, Department of Internal Medicine and The Hadassah Diabetes Center, Hadassah Hebrew University \\ Medical Center, Jerusalem, Israel \\ ${ }^{2}$ Department of Biology, Faculty of Natural Sciences, Haifa University, Beit Mitzpor, Oranim, Tivon 36006, Israel \\ (Submitted 29 June 2011 - Final revision received 20 September 2011 - Accepted 13 October 2011 - First published online 15 December 2011)
}

\section{Abstract}

In search for an effective oral treatment for diabetes, we examined the capacity of glucose tolerance factor (GTF) extracted from yeast and administered orally to reduce hyperglycaemia in rat models exhibiting insulin deficiency. The cellular effect of GTF on the insulin signalling pathway was investigated in vitro. GTF (oral bolus), insulin (intraperitoneal) or their combination was administered to streptozotocindiabetic (STZ) or hyperglycaemic Cohen diabetic-sensitive (hyp-CDs) rats. Blood glucose (BG) and insulin levels were measured in the postprandial (PP) state and during an oral glucose tolerance test. Deoxy-glucose transport and insulin signal transduction were assessed in 3T3-L1 adipocytes and myoblasts incubated with the GTF. Low dose of insulin produced a 34 and $12.5 \%$ reduction in the PP-BG levels of hyp-CDs and STZ rats, respectively. GTF induced a 33 and $17 \%$ reduction in the PP-BG levels of hyp-CDs and STZ rats, respectively. When combined with insulin, a respective decrease (58 and $42 \%$ ) in BG levels was observed, suggesting a partially additive (hyp-CDs) or synergistic (STZ rats) effect of the GTF and insulin. GTF did not induce insulin secretion in hyp-CDs rats, yet it lowered their BG levels, proposing an effect on glucose clearance by peripheral tissues. GTF induced a dose-dependent increase in deoxy-glucose transport into myoblasts and fat cells similar to insulin, while the combined treatment resulted in augmented transport rate. GTF induced a dose- and timedependent phosphorylation of insulin receptor substrate 1 , Akt and mitogen-activated protein kinase independent of insulin receptor phosphorylation. GTF exerts remarkable insulin-mimetic and insulin-potentiating effects, both in vivo and in vitro. It produces an insulin-like effect by acting on cellular signals downstream of the insulin receptor. These results demonstrate a potential source for a novel oral medication for diabetes.

\section{Key words: Diabetes: Yeast: Glucose tolerance factor: Glucose-lowering effect: Insulin signalling}

Drug treatment options for diabetes mellitus are many and diverse. Despite the use of intensive regimens combining several anti-diabetic drugs and insulin, glycaemic control declines over time in most diabetic patients, reflecting ongoing deterioration of $\beta$-cell function. As a consequence, much research has focused on identifying new therapeutic targets and pharmacological compounds that might correct impaired glucose homeostasis via novel pathways. In recent years, there has been an increased interest in anti-diabetic natural products $^{(1-3)}$ : materials that mimic insulin action or augment the effect of residual endogenous insulin are likely to be beneficial for both type 1 and 2 diabetic patients.

Binding of insulin to its receptor initiates a cascade of phosphorylation of several substrates, including insulin receptor substrate (IRS) proteins. IRS-1 is widely expressed in insulin-sensitive tissues, and it transmits the signal from insulin receptor to biological endpoints, such as glucose transport, protein, lipid and glycogen synthesis ${ }^{(4)}$. Phosphorylation of IRS-1 subsequently triggers the activation of downstream signal molecules such as phosphatidylinositol 3-kinase $(\mathrm{PI} 3 \mathrm{~K})$, protein kinase $\mathrm{B}(\mathrm{PKB} / \mathrm{AKT})$ and several isoforms of protein kinase $\mathrm{C}$ (PKC) (atypical, conventional and novel categories of protein kinase $\mathrm{C}$ ), and mitogen-activated protein kinase (MAPK) can also interact directly with IRS-1 ${ }^{(4)}$.

Glucose tolerance factor (GTF) is a dietary agent first extracted by Schwarz and Mertz from Brewer's yeast ${ }^{(5)}$. Subsequent experiments showed that this partially purified extract lowered blood glucose (BG) and lipids in diabetic animals and affected both glucose and fatty acid metabolism in insulinresponsive cells ${ }^{(6-10)}$.

Abbreviations: BG, blood glucose; BW, body weight; DM, diabetes mellitus; GTF, glucose tolerance factor; HSD, high-sucrose diet; hyp-CDs, hyperglycaemic Cohen diabetic-sensitive; IRS, insulin receptor substrate; MAPK, mitogen-activated protein kinase; OGTT, oral glucose tolerance test; PP, postprandial; STZ, streptozotocin.

*Corresponding author: N. Mirsky, fax +972 153 777930138, email nmirsky@bezeqint.net 
Despite the potential importance of this natural substance, it has not been fully characterised and the active substance has not yet been identified, mainly due to the instability of the purified fractions. We extracted and partially purified an active and stable GTF preparation from brewer's yeast. Although our preparation is not fully characterised, we found that it has a low molecular weight, is stable to proteolytic enzymes, and therefore can be orally administered ${ }^{(11-13)}$. In the present study, we show the ability of our active and stable GTF preparation to reduce hyperglycaemia in two rat models exhibiting insulin deficiency: the streptozotocin (STZ) diabetic rat, which is characterised by the loss of $\beta$-cells, and the hyperglycaemic Cohen diabetic-sensitive (hyp-CDs) rat, which is characterised by $\beta$-cell dysfunction and diminished glucose-stimulated insulin secretion ${ }^{(14,15)}$. We also demonstrate the cellular mechanism underlying the glucose-lowering properties of the GTF.

\section{Experimental methods}

\section{Preparation of the glucose tolerance factor}

GTF was prepared as described previously ${ }^{(11)}$. Briefly, the method is based on methanolic extraction, separation through different membranes (cut-off 3500 and $1000 \mathrm{Da}$ ), ion-exchange columns and gel filtration. Several active fractions with higher biological activity were isolated by HPLC C18 and gel filtration columns.

\section{Animals and diet}

Male CDs rats were bred and maintained in the animal facility, Hebrew University School of Medicine, Jerusalem, Israel. Diabetes was induced in 7-week-old male CDs rats weighing $120 \mathrm{~g}$ by a diabetogenic high-sucrose diet (HSD) provided for a period of 1 month. The HSD is custom-prepared in our laboratory. The HSD contains $72 \%$ sucrose, $18 \%$ vitamin-free casein, 5\% salt mixture no. II USP (MP Biomedicals, LLC, Cleveland, OH, USA), $4.5 \%$ butter, $0.5 \%$ maize oil, vitamins and low copper $(0.9 \text { parts per million })^{(14,15)}$.

Male Sprague-Dawley rats (5 weeks old) weighing $120 \mathrm{~g}$ were purchased from Harlan Israel. Diabetes was induced by a single subcutaneous injection of STZ $(60 \mathrm{mg} / \mathrm{kg}$ body weight (BW)) dissolved in $50 \mathrm{~mm}$-citrate buffer ( $\mathrm{pH} 4.5)$. Only diabetic animals (STZ or hyp-CDs) with non-fasting glycaemia $>2000 \mathrm{mg} / \mathrm{l}>200 \mathrm{mg} / \mathrm{dl}$ were included in the study. Animal studies were approved by the institutional committees for animal use and care.

\section{Experimental design}

In vivo studies included determination of $\mathrm{BG}$ levels in the postprandial (PP) state, and during the oral glucose tolerance test (OGTT) and the insulin tolerance test. Overnight fasted hyp-CDs and STZ rats were treated with the GTF at two oral doses: 0.6 and $1.2 \mathrm{~g} / 100 \mathrm{~g}$ BW to hyp-CDs rats and $0.8 \mathrm{~g}$ / $100 \mathrm{~g}$ BW to STZ rats. Glucose concentration was measured in tail blood using a standard glucometer (Elite ${ }^{\circledR}$; Bayer,
Leverkusen, Germany). Serum insulin was determined using an ultrasensitive rat insulin ELISA assay (Mercodia AB, Uppsala, Sweden). In vitro studies comprised investigation of the cellular mechanism of the GTF and its involvement in the insulin signalling pathway. These studies were performed in myoblasts and differentiated 3T3-L1 adipocytes.

\section{In vivo studies}

Oral glucose tolerance test. BG and insulin levels were measured after an overnight fast. Then, rats were administered orally with the GTF. The OGTT was performed $30 \mathrm{~min}$ after GTF administration. BG and insulin levels were measured at 30,60 and $120 \mathrm{~min}$ following glucose administration, $3.5 \mathrm{~g} / \mathrm{kg}$ for hyp-CDs rats ${ }^{(15)}$ and $2 \mathrm{~g} / \mathrm{kg}$ for STZ rats.

Postprandial test. Hyp-CDs rats fasted overnight had free access to the HSD for a period of $60 \mathrm{~min}$. At time $0, \mathrm{BG}$ levels were measured, the HSD was removed and the GTF was administered orally ${ }^{(14,15)}$. STZ rats had free access to Purina chow during the night. At time 0 , the food was removed, BG levels were measured and the GTF was administered orally. BG levels were assessed in both diabetic models after 60 and $120 \mathrm{~min}$ of food removal and GTF administration.

\section{Insulin tolerance test}

BG concentrations were measured after an overnight fast and during $120 \mathrm{~min}$ following an intraperitoneal (IP) administration of insulin $(1.14 \mu \mathrm{g} / \mathrm{kg}$ for hyp-CDs rats and $6.8 \mu \mathrm{g} / \mathrm{kg}$ for STZ rats, Actrapid ${ }^{\circledR}$ HM; Novo Nordisk, Denmark), as specified in the different studies.

\section{In vitro studies}

Rat L6 myoblasts were grown in minimum essential medium with glucose $(1 \mathrm{~g} / \mathrm{l})$, glutamine $(4 \mathrm{mmol} / \mathrm{l})$, penicillin $(30 \mu \mathrm{g} /$ $\mathrm{ml})$, streptomycin $(50 \mathrm{mg} / \mathrm{ml})$ and fetal bovine serum $(10 \%$, $\mathrm{v} / \mathrm{v})$. 3T3-L1 cells were grown in Dulbecco's modified Eagle's medium with glucose $(4.5 \mathrm{~g} / \mathrm{l})$, glutamine $(4 \mathrm{mmol} / \mathrm{l})$, penicillin $(30 \mu \mathrm{g} / \mathrm{ml})$, streptomycin $(50 \mathrm{mg} / \mathrm{ml})$ and fetal bovine serum $(10 \%, \mathrm{v} / \mathrm{v})$. The cells were grown at $37^{\circ} \mathrm{C}$ in a humidified atmosphere of $5 \% \mathrm{CO}_{2}$. Differentiation of $3 \mathrm{~T} 3$ cells was induced with differentiation medium: Dulbecco's modified Eagle's medium, 10\% fetal bovine serum, $0.5 \mathrm{~mm}-$ 3-isobutyl-1-methylxanthine, $1 \mu \mathrm{m}$-dexamethasone and $5 \mu \mathrm{g}$ insulin $/ \mathrm{ml}$. Before the treatment, cells were serum starved in Dulbecco's modified Eagle's medium with $0 \cdot 1 \%$ bovine serum albumin for $16-18 \mathrm{~h}$. Insulin (100 nm) or GTF (5$20 \mathrm{mg} / \mathrm{ml}$ ) was added. Cells were lysed in Ripa lysis buffer. Western blot analysis was performed with antibodies for phosphorylated proteins (IRS-1, Akt or MAPK), followed by stripping and reblotting with antibodies for total protein as a loading control.

\section{2-Deoxy-glucose uptake}

Glucose transport was assessed by measuring the uptake of $\left[{ }^{3} \mathrm{H}\right] 2$-deoxy-D-glucose in PBS ( $\mathrm{pH} 7 \cdot 4$ ), containing 0.05 mmol 
$\left[{ }^{3} \mathrm{H}\right] 2$-deoxy-D-glucose $/ 1$ (specific activity $0.023 \mu \mathrm{Ci} / \mu \mathrm{mol}$ ) at $37^{\circ} \mathrm{C}$. Differentiated 3T3-L1 adipocytes were serum starved for $5 \mathrm{~h}$. Cells were exposed to GTF, insulin or their combination. The cells were dissolved in $1 \mathrm{~m}-\mathrm{NaOH}$, and aliquots were taken for liquid scintillation counting and protein determination.

\section{Quantification and statistics}

Data are expressed as means with standard errors. Quantitative assessment of phosphorylated protein bands detected by Western blotting was performed by densitometry of films and subsequent analysis using the program Image $\mathrm{J}$ (from the National Institute of Health). Results are expressed as arbitrary units, and statistical significance was determined using two-tailed Student's $t$ test.

The significance of differences between the experimental and control values was evaluated using a non-paired, twotailed Student's $t$ test

\section{Results}

In vivo studies

Oral glucose tolerance test. Control vehicle-treated hyp-CDs and STZ rats exhibited an abnormal glucose tolerance curve, characterised by elevated BG levels (Fig. 1(a) and (b)). Administration of the GTF lowered the calculated BG area under the curve of hyp-CDs rats compared with vehicle-treated hyp-CDs rats. The decrease in BG-area under the curve depended on the dose of the GTF administered ( 6 and $20 \%$ for 0.6 and $1.2 \mathrm{~g} / 100 \mathrm{~g}$ BW, respectively; Fig. 1(a)). GTF ( $0.8 \mathrm{~g} / 100 \mathrm{~g}$ BW) reduced BG-area under the curve of STZ rats by $43 \%$ compared with vehicle-treated STZ rats (Fig. 1(b)). Although the values detected for fasting BG in both STZ and hyp-CDs rats were not elevated, their OGTT were remarkably different from healthy animals. Insulin secretion in response to glucose stimulation did not change significantly in GTF-treated hyp-CDs rats (3494 (sEm 632) pmol/1) compared with vehicle-treated rats $(4128$ (SEM 467$) \mathrm{pmol} / \mathrm{l})$, suggesting that the glucose-lowering effect of the GTF is not related to the stimulation of insulin secretion.

Postprandial blood glucose concentrations. In the vehicletreated hyp-CDs and STZ rats, the markedly elevated BG concentrations (time 0) remained high for more than $120 \mathrm{~min}$ (Fig. 2(a) and (b)). GTF administration significantly reduced $(P<0.001)$ the high BG concentrations in both hyp-CDs (33\%) and STZ rats (38\%).

Combined treatment of glucose tolerance factor and insulin. The effect of the low doses of insulin, GTF or their combination on PP-BG levels of the treated animals is presented in Fig. 3(a) and (b). A single low dose of insulin produced a reduction of 34 and $12.5 \%$ in the PP-BG levels of hyp-CDs and STZ rats, respectively. The difference in insulin effect between the two animal models can be explained by the very high sensitivity to insulin, detected in hyp-CDs rats. A bolus dose of the GTF ( 1.2 and $0.8 \mathrm{~g} / 100 \mathrm{~g} \mathrm{BW})$ induced a respective decrease of 33 and $17 \%$ in the PP-BG levels of hyp-CDs and STZ rats. The combination of GTF and insulin resulted in a respective decrease of 58 and $42 \%$, indicating a partially additive effect (hyp-CDs rats) or a synergistic effect (STZ rats) of GTF and insulin.

\section{In vitro studies}

Glucose uptake. A marked increase in 2-deoxy-glucose uptake in L6 myoblasts and 3T3-L1 adipocytes was induced by the GTF (Fig. 4(a) and (b); Table 1). Fig. 4(a) presents 2-deoxy-glucose uptake in L6 cells with the addition of insulin or GTF. It can be seen that insulin (10, 50 and $100 \mathrm{~nm})$ increased the rate of 2-deoxy-glucose uptake by 160, 209 and $214 \%$, respectively. GTF $(10 \mathrm{mg} / \mathrm{ml})$ increased the rate of uptake by $164 \%$, indicating a high positive effect on glucose (a)

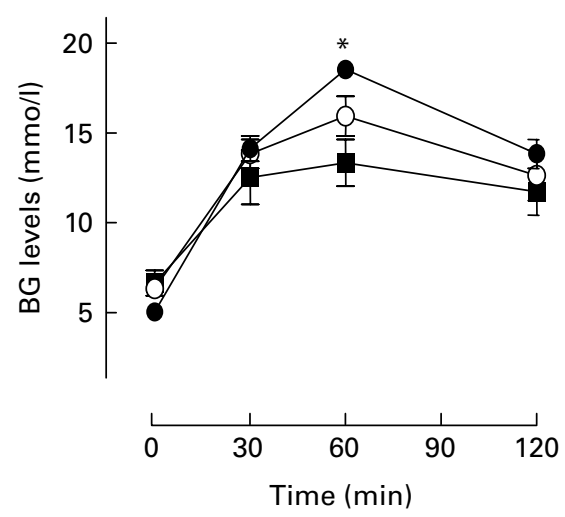

(b)

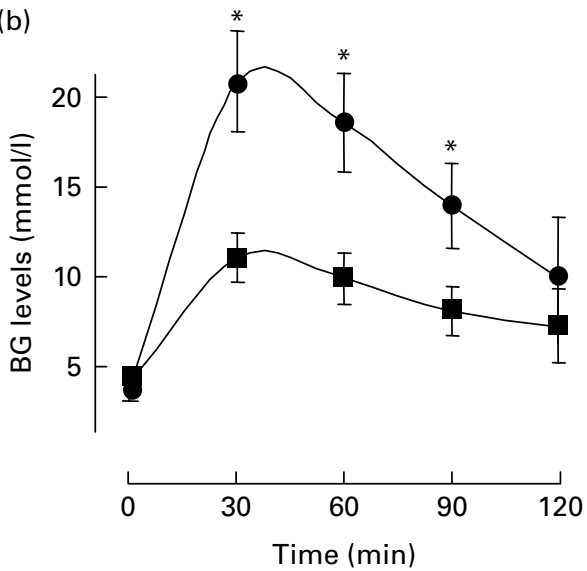

Fig. 1. Oral glucose tolerance test (OGTT) of glucose tolerance factor (GTF)-treated diabetic rats. (a) OGTT profiles of diabetic untreated hyperglycaemic Cohen diabetic-sensitive (hyp-CDs) rats $(\bullet)$, GTF-treated $(0.6 \mathrm{~g} / 100 \mathrm{~g}$ body weight $(\mathrm{BW})$ ) hyp-CDs rats (O) and GTF-treated (1.2 $\mathrm{g} / 100 \mathrm{~g}$ BW) hyp-CDs rats ( $\mathbf{\square})$.

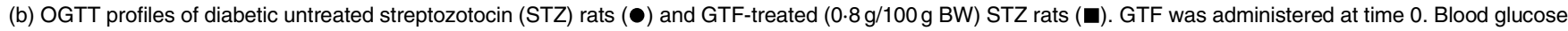
(BG) levels were measured after an overnight fast (0), and at 30, 60 and $120 \mathrm{~min}$ after glucose administration (3.5 g/kg for hyp-CDs rats and $2 \mathrm{~g} / \mathrm{kg}$ for STZ rats). Values are means, with their standard errors represented by vertical bars for five or six animals per group. * Mean values were significantly different for diabetic from those of untreated control $(P<0.001)$. 
(a)

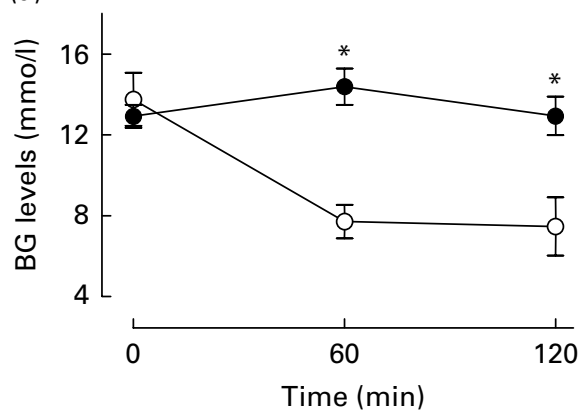

(b)

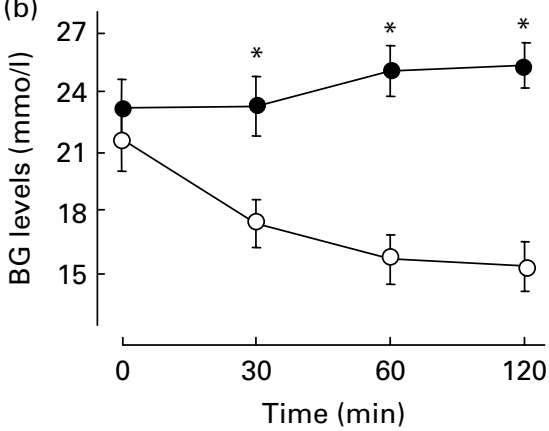

Fig. 2. Postprandial (PP) glucose levels in glucose tolerance factor (GTF)-treated diabetic rats. (a) PP glucose levels of control untreated hyperglycaemic Cohen diabetic-sensitive (hyp-CDs) rats $(\bullet)$ and GTF-treated $(1.2 \mathrm{~g} / 100 \mathrm{~g}$ body weight $(\mathrm{BW}))$ hyp-CDs rats (O). Hyp-CDs rats fasted overnight had free access to a highsucrose diet (HSD) for a period of $60 \mathrm{~min}$. At time 0 , the HSD was removed, the blood glucose (BG) levels were measured and the GTF was administered to the indicated groups. (b) Postprandial glucose levels of untreated streptozotocin (STZ) rats $(\bullet)$ and GTF-treated $(0.8 \mathrm{~g} / 100 \mathrm{~g} \mathrm{BW}) \mathrm{STZ}$ rats (O). Rats had free access to food during the night. Food was removed at time 0 and the BG levels were measured. Also, the GTF was administered to the indicated groups. The BG levels were also assessed after 60 and 120 min from food removal. Values are means, with their standard errors represented by vertical bars for five or six animals per group. * Mean values were significantly different for diabetic from those of untreated control $(P<0.001)$.

uptake. Fig. 4(b) presents 2-deoxy-glucose uptake in 3T3 adipocytes with increasing doses of the GTF. The curve indicates a dose-dependent increase in glucose uptake induced by the GTF. Table 1 shows the effect of the low doses of insulin $(45.5 \mathrm{ng} / \mathrm{ml})$, GTF $(5 \mathrm{mg} / \mathrm{ml})$ or the combination of the two agents on 2-deoxy-glucose uptake in 3T3 adipocytes. GTF induced more than two times increase in the rate of glucose transport; insulin induced more than three times increase, while the combination of the two agents resulted in about nine times increase. Thus, the combined treatment of GTF and insulin resulted in the increased rate of deoxyglucose transport that exceeded the sum of the two separate treatments, indicating synergy between the GTF and insulin.

Phosphorylation and activation of key proteins along the insulin cellular pathway. A marked stimulation of tyrosine phosphorylation on IRS1 was induced by the GTF (Fig. 5). The values for IRS1 phosphorylation by the GTF were

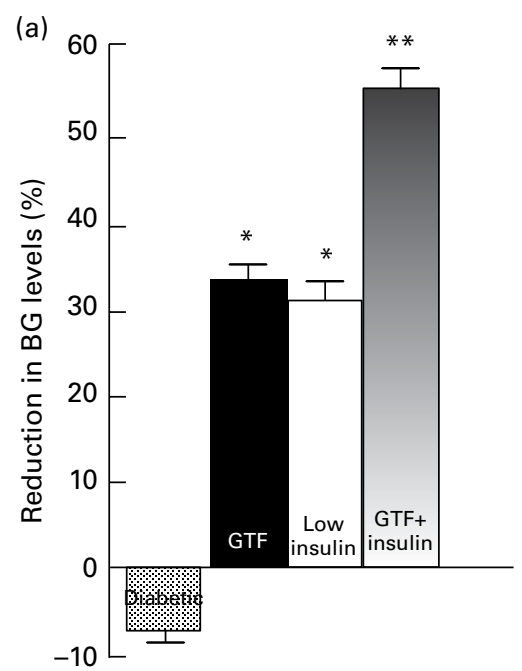

similar to those obtained by insulin. GTF stimulated Akt phosphorylation in a dose- (data not shown) and timedependent manner (Fig. 6). A similar effect on P44/42 MAPK phosphorylation was also induced by the GTF (Fig. 7). The phosphorylation obtained by the GTF was similar to that induced by insulin. However, we did not find any augmented phosphorylation of the insulin receptor by the addition of the GTF.

\section{Discussion}

The findings described in the present study indicate the high potential of the GTF as insulin-mimetic material both in vivo and in vitro. We found that GTF is a glucose-lowering agent in two types of diabetic animals and presented data showing that its cellular mechanism follows the insulin signalling pathway.

(b)

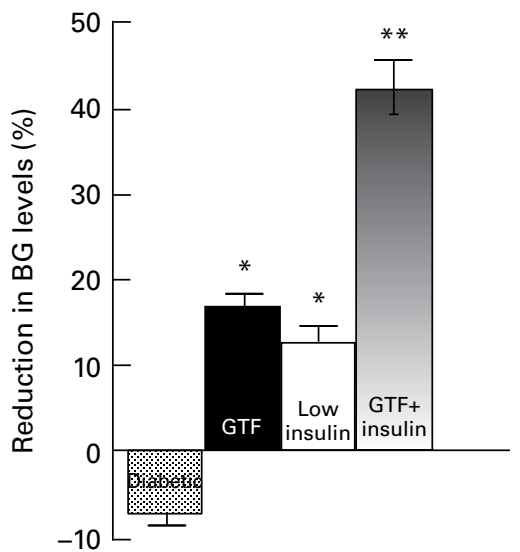

Fig. 3. Insulin action is enhanced by the glucose tolerance factor (GTF). Percentage reduction of the 120 min postprandial (PP) glucose level of (a) untreated hyperglycaemic Cohen diabetic-sensitive (hyp-CDs) rats (图), GTF-treated (1.2 g/100 g body weight (BW)) hyp-CDs rats ( $\mathbf{0})$, low-insulin-treated (1.14 $\mu \mathrm{g} / \mathrm{kg})$ hyp-CDs rats ( $\square$ ) and GTF + low-insulin-treated hyp-CDs rats ( $\square$ ). (B) Untreated streptozotocin (STZ) rats (圈), GTF-treated (0.4 g/100 g BW) STZ rats ( $\square$ ), lowinsulin-treated $(6.8 \mu \mathrm{g} / \mathrm{kg})$ STZ rats $(\square)$ and GTF + low-insulin-treated STZ rats $(\square)$. Values are means, with their standard errors represented by vertical bars for five or six animals per group. Mean values were significantly different for diabetic from those of untreated controls: ${ }^{\star} P<0 \cdot 01$, ${ }^{\star \star} P<0 \cdot 001$. BG, blood glucose. 

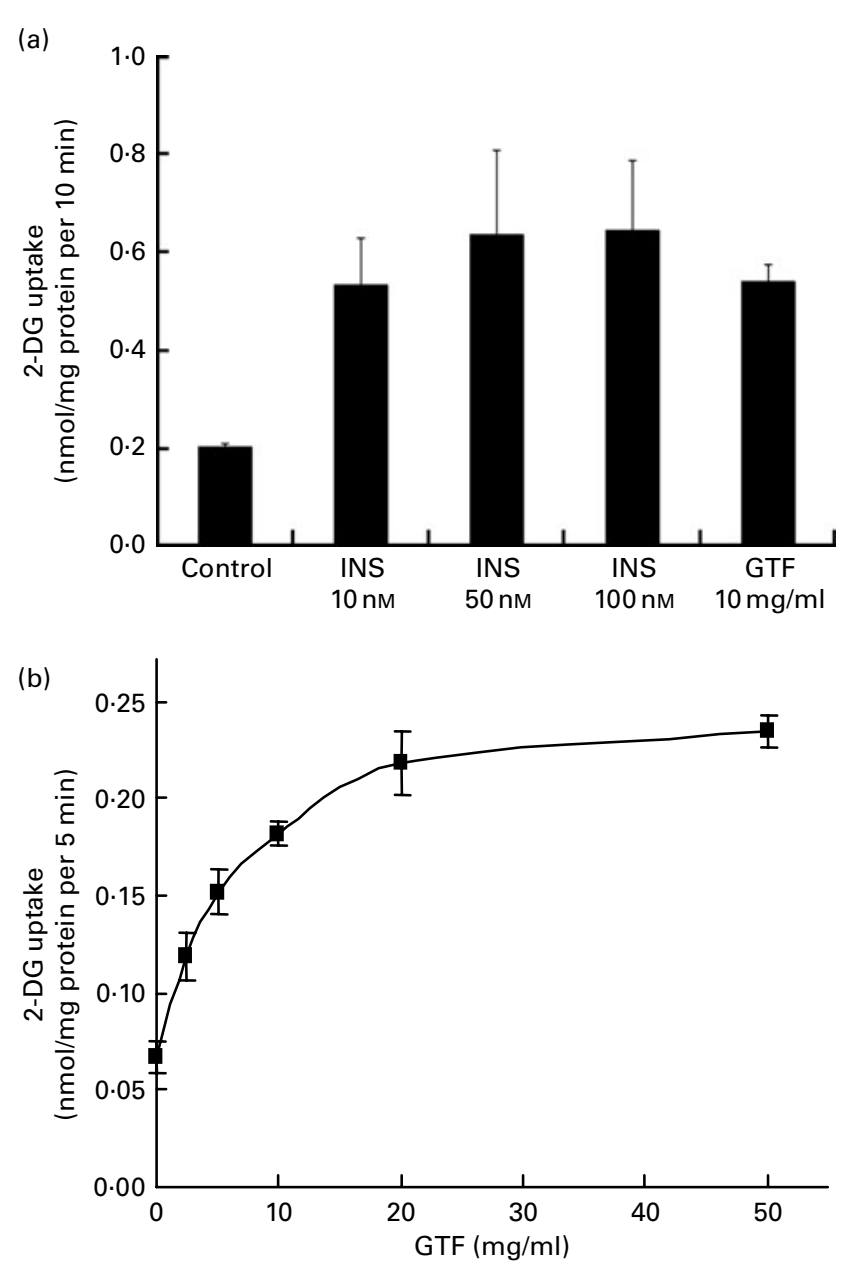

Fig. 4. (a) Glucose tolerance factor (GTF) increases 2-deoxy-glucose (2-DG) uptake in L6 cells. L6 myoblasts were washed with PBS ( $\mathrm{pH} \mathrm{7.4)}$ and incubated in serum-free medium for $5 \mathrm{~h}$. The medium was removed and the cells were incubated with $1.5 \mathrm{ml} /$ well buffer $\mathrm{A}\left(1.47 \mathrm{mM}-\mathrm{K}_{2} \mathrm{HPO}_{4}, \mathrm{pH} 7.4,140 \mathrm{~mm}\right.$ $\mathrm{NaCl}, 1.7 \mathrm{~mm}-\mathrm{KCl}, 0.9 \mathrm{~mm}-\mathrm{CaCl}_{2}, 0.9 \mathrm{~mm}-\mathrm{MgSO}_{4}$ and $0.1 \%$ bovine serum albumin) with the specific addition for $1 \mathrm{~h}$. The cells were washed with PBS, and incubated for additional $10 \mathrm{~min}$ with radiolabelled $\left[{ }^{3} \mathrm{H}\right] 2-\mathrm{DG}(0.05 \mathrm{mmol} / \mathrm{l})$. The cells were washed with cold $\left(4^{\circ} \mathrm{C}\right) \mathrm{PBS}$, and dissolved in $1 \mathrm{M}-\mathrm{NaOH}$. Aliquots were taken for liquid scintillation counting and protein determination. Zero time counts were subtracted. Non-specific glucose uptake was determined with $20 \mu \mathrm{M}$-cytochalasin B and subtracted from the total counts measured. (b) GTF increases 2-DG uptake in 3T3-L1 adipocytes. Glucose transport was measured in $3 T 3-\mathrm{L} 1$ adipocytes in PBS $\left(\mathrm{pH} \mathrm{7.4)}\right.$ ), at $37^{\circ} \mathrm{C}$, with the addition of $0.05 \mathrm{~mm}-\left[^{3} \mathrm{H}\right] 2-\mathrm{DG}$. Different concentrations of the GTF $(0-20 \mathrm{mg} / \mathrm{ml})$ were assayed. Incubation time was $1 \mathrm{~h}$. Cells were dissolved in $1 \mathrm{M}-\mathrm{NaOH}$, and aliquots were taken for scintillation counting and protein determination. Values are means, with their standard errors represented by vertical bars for three to four plates. Mean values were significantly different for plates in all experiments $(P<0.05)$. INS, insulin.

Many attempts have been made during the past decades to isolate pure GTF from brewer's yeast and to determine its chemical structure ${ }^{(11,16-18)}$. Most of these attempts failed due to the instability of the purified fractions ${ }^{(9,10,19)}$.

In the present study, we used a partially purified but active and stable GTF fraction prepared in our laboratory according to a modification of a method developed by us ${ }^{(11)}$. We found previously that administration of repeated doses of the GTF to diabetic rats not only decreased their BG but also reduced their blood lipids and decreased lipid oxidation processes in organs such as heart and kidney ${ }^{(13,20)}$. Moreover, when the GTF was given at an early stage of the disease, it could prevent or delay diabetes complications such as nephropathy and retinopathy ${ }^{(20)}$.

In the present study, we showed that administration of a single oral dose of the GTF decreased PP-BG levels and improved fasting OGTT in both STZ and hyp-CDs rats, two different models exhibiting reduced blood insulin concentration. In hyp-CDs rats, we demonstrated a dose-dependent reduction in BG levels that was not accompanied by an increase in blood insulin concentration. Thus, the glucoselowering outcome of the GTF is likely to be attributed to increased glucose clearance by peripheral tissues and not to induced insulin secretion.

The glucose-lowering effects of the GTF in both animals and diabetic patients have been first demonstrated by $\operatorname{Mertz}^{(7,19)}$, and later by others ${ }^{(9,10,13,20,21)}$. Several researchers have suggested that GTF decreased the elevated BG levels by potentiating the effect of endogenous insulin ${ }^{(10,21,22)}$. Additional investigators have reported that the effect of the GTF on cellular glucose metabolism was dependent on the presence of insulin ${ }^{(6,10,16,18,21)}$, while other studies have shown that GTF acted independently of insulin ${ }^{(8,23)}$.

Several theories have been suggested for the potential correlation between GTF activity and insulin: from a direct binding of GTF to insulin ${ }^{(22,24)}$, to the activity of the GTF as a cofactor for insulin by enhancing insulin binding to its receptors ${ }^{(5,6,16,17,25)}$. In the present study, we showed an increased glucose-lowering effect of the GTF when combined with low doses of insulin for the two hyperglycaemic rat models. In hyp-CDs rats, a partially additive effect was observed, whereas in STZ rats, the effect was synergistic. In hyp-CDs rats, a very small dose of insulin produced a high reduction in PP-BG levels. The combination of the GTF with insulin showed some higher effect than each agent separately. In STZ rats, much higher effect was observed for the combination of GTF and insulin. The difference between the two models can be explained by their difference in peripheral sensitivity to insulin: in hyp-CDs rats, no peripheral resistance to insulin was observed ${ }^{(14,15)}$, while the STZ rats were less sensitive to insulin. Furthermore, since a marked glucose-lowering

Table 1. Effect of insulin, glucose tolerance factor (GTF) and their combination on 2-deoxy-glucose (2-DG) transport in 3T3-L1 adipocytes† (Mean values with their standard errors of weights in $\mathrm{g}$ )

\begin{tabular}{|c|c|c|c|}
\hline \multirow[b]{2}{*}{ Treatments } & \multirow[b]{2}{*}{ Concentration } & \multicolumn{2}{|c|}{$\begin{array}{l}\text { 2-DG transport } \\
\text { (nmol/mg protein } \\
\text { per } 5 \mathrm{~min} \text { ) }\end{array}$} \\
\hline & & Mean & SEM \\
\hline Control & & 0.067 & 0.001 \\
\hline Insulin & $45.5 \mathrm{ng} / \mathrm{ml}$ & $0.225^{\star}$ & 0.015 \\
\hline GTF & $5 \mathrm{mg} / \mathrm{ml}$ & $0.152^{*}$ & 0.006 \\
\hline Insulin + GTF & $45.5 \mathrm{ng} / \mathrm{ml}+5 \mathrm{mg} / \mathrm{ml}$ & $0.597^{*}$ & 0.047 \\
\hline
\end{tabular}



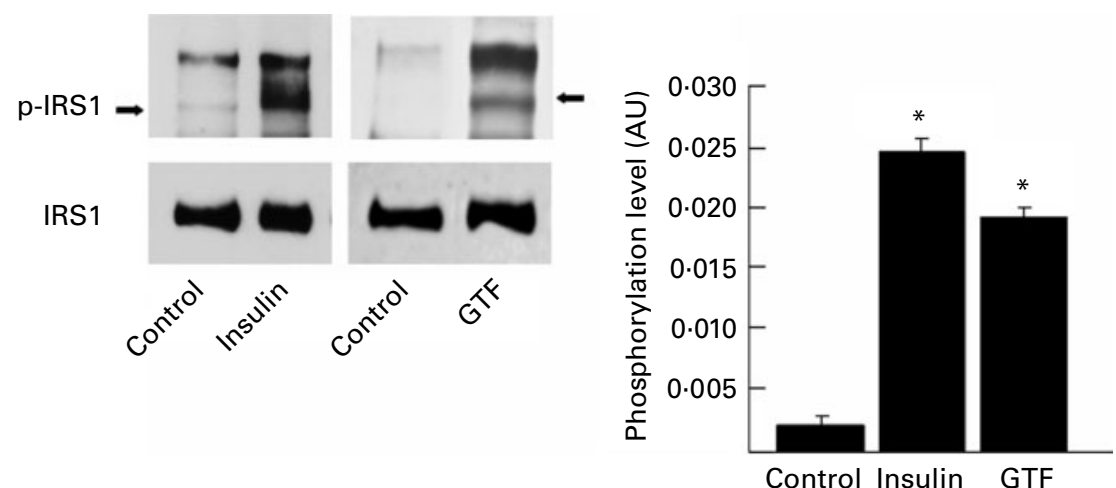

Fig. 5. Glucose tolerance factor (GTF) stimulates tyrosine phosphorylation on insulin receptor substrate 1 ( $p$-IRS1). Differentiated $3 T 3-L 1$ adipocytes were serum starved for $18 \mathrm{~h}$. Cells were treated with $100 \mathrm{nM}$-insulin for $1 \mathrm{~min}$ or with GTF $(20 \mathrm{mg} / \mathrm{ml})$ for 15 min. Cells were lysed and Western blot analysis was performed with antibodies for phosphotyrosine, followed by stripping and reblotting with antibodies for total IRS1 as a loading control. Quantification of the bands of p-IRS1 (mean) is based on scanning densitometry of three independent immunoblots, with standard errors represented by vertical bars. AU, arbitrary units. ${ }^{\star} P<0.05$.

effect of the GTF was demonstrated when given alone, we concluded that GTF may potentiate insulin effect but does not require insulin for its action. Thus, GTF may be considered as both insulin mimicker and insulin potentiator, depending on the physiological set-up.

The present in vitro studies strengthen the in vivo findings. We found an increase in 2-deoxy-glucose transport in L6 myoblasts and in 3T3 adipocytes when GTF was added to the medium. The present results indicate that GTF enhanced glucose uptake in two target tissues known for their sensitivity to insulin: muscle cells (represented by L6 myoblasts), which utilise a high portion of glucose entering the body, and fat cells (3T3 adipocytes), also known to increase glucose transport following insulin addition.

We also demonstrated that glucose uptake in 3T3 cells achieved by the combination of both GTF and insulin was much higher than the sum of the effects, when the two agents were added separately (Table 1), also indicating a synergistic effect in vitro.

Mertz and co-workers defined GTF as a Cr complex of nicotinic acid and three amino acids (glycine, cystein and

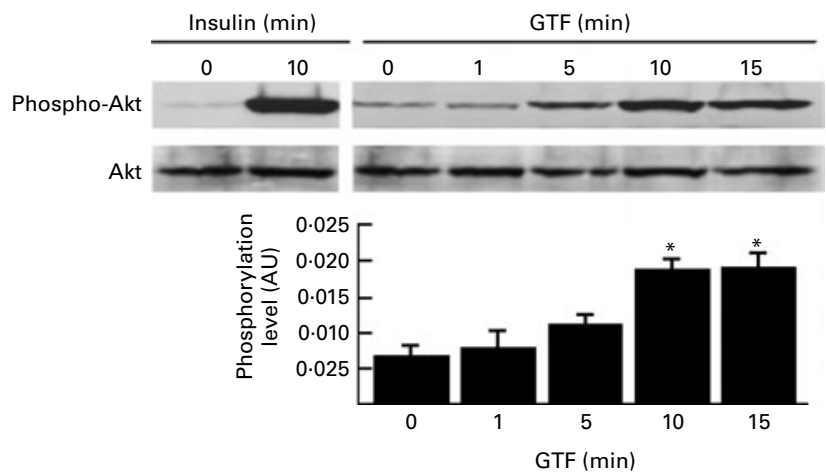

Fig. 6. Glucose tolerance factor (GTF) stimulates Akt phosphorylation (phospho-Akt). Differentiated 3T3-L1 adipocytes were serum starved for $18 \mathrm{~h}$. Cells were treated with $100 \mathrm{~nm}$-insulin for $10 \mathrm{~min}$ or with GTF $(20 \mathrm{mg} / \mathrm{ml})$ for $1,5,10$ or $15 \mathrm{~min}$. Cells were lysed and Western blot analysis was performed with antibodies for phospho-Akt, followed by stripping and reblotting with antibodies for total Akt as a loading control. Quantification of the bands of phospho-Akt (mean) is based on scanning densitometry of three independent immunoblots, with standard errors represented by vertical bars. $A U$, arbitrary units. ${ }^{\star} P<0.05$. glutamic acid $)^{(18,24)}$. Several attempts to synthesise Cr complexes with nicotinic acid and the three amino acids concluded with unstable complexes that were much inferior in their activity to the natural $\mathrm{GTF}^{(18,24)}$. Moreover, GTF activity did not differ between extracts derived from Cr-rich and Cr-deficient yeast $^{(16,25,26)}$, indicating that there is no direct correlation between Cr content and GTF activity. Several studies that were done to purify and identify GTF extracted from yeast did not find a correlation between GTF activity and Cr content ${ }^{(16,17,25)}$. Recently, using more accurate methods for determination of trace elements, we also did not find $\mathrm{Cr}$ in the isolated active fractions ( $\mathrm{N}$ Mirsky, $\mathrm{T}$ Mizrahi and $\mathrm{N}$ Shitrit, unpublished results).

What is the cellular mechanism underlying the glucoselowering properties of the glucose tolerance factor?

In vitro studies showed that GTF increased insulin effect on glucose uptake and incorporation in adipocytes, cardiomyocytes and hepatocytes ${ }^{(6,8,22)}$. We demonstrated that the addition of the GTF increased the transport of deoxy-glucose in adipocytes and myoblasts in an insulin-like mode. In order to elucidate the mechanism by which the GTF operates, we investigated the effects of the GTF on key proteins along the insulin cellular cascade. The first important event in the insulin cellular pathway is the activation of the insulin receptor $\beta$-subunit, followed by the activation of one of its major substrates, IRS1, obtained by the phosphorylation of tyrosine residues. These result in the activation of three major pathways, the phosphatidylinositol 3-kinase/Akt pathway, the Cbl pathway (considered as a phosphatidylinositol 3-kinase-independent pathway) and the MAPK pathway ${ }^{(4)}$.

The present data demonstrate that GTF stimulated a cascade of time- and dose-dependent phosphorylation in a similar mode to that obtained by insulin. In contrast to insulin, our preliminary studies in both 3T3 and L6 cells could not demonstrate any direct effect of the GTF on tyrosine phosphorylation of the insulin receptor $\beta$-subunit in any of the doses or the time points examined. However, the present data do show that GTF-stimulated tyrosine phosphorylation on IRS1 and a serine/threonine phosphorylation of Akt (protein kinase B), demonstrating the ability of the GTF to phosphorylate several 
Insulin-mimetic factor extracted from yeast

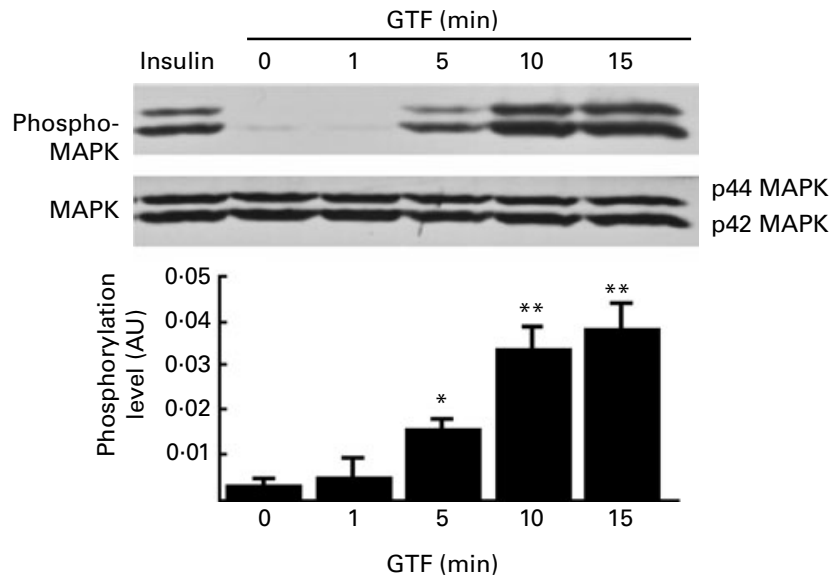

Fig. 7. Glucose tolerance factor (GTF) stimulates mitogen-activated protein kinase (MAPK) phosphorylation (phospho-MAPK). Differentiated 3T3-L1 adipocytes were serum starved for $18 \mathrm{~h}$. Cells were treated with $100 \mathrm{~nm}$-insulin for $10 \mathrm{~min}$ or with GTF $(20 \mathrm{mg} / \mathrm{ml})$ for $1,5,10$ or $15 \mathrm{~min}$. Cells were lysed and Western blot analysis was performed with antibodies for phospho-p42/44 MAPK, followed by stripping and reblotting with antibodies for total p42/44 MAPK as a loading control. Quantification of the bands of p42/44 MAPK (mean) is based on scanning densitometry of three independent immunoblots, with standard errors represented by vertical bars. AU, arbitrary units. ${ }^{\star} P<0.05,{ }^{* \star} P<0.01$.

key proteins in the insulin signalling pathway in the absence of insulin, supporting the notion that the beneficial effect of the GTF on glucose uptake is mediated directly by mediators in insulin-glucose transport transduction. This hypothesis has already been suggested in our previous study in yeast cells ${ }^{(12)}$ and is reinforced by the data presented in the present study.

Insulin also mediates the activation of the MAPK cascade resulting in nuclear activity and mitogenesis. In the present study, we showed an increased phosphorylation of $44 / 42$ MAPK in 3T3-L1 adipocytes in response to the GTF, indicating the participation of the GTF also in processes involving nuclear activity. These observations are also in concert with our previous results ${ }^{(27)}$, demonstrating increased growth of yeast cells when the GTF was added to the medium. However, since, as mentioned above, we did not find any increase in tyrosine phosphorylation on the insulin receptor $\beta$-subunit following the addition of the GTF, we suggest that GTF does not exert its effects via the insulin receptor but in a different pathway, not yet identified, involving cellular signals regulating glucose transport and nuclear activity, in an insulin-like manner.

Our recent studies on P69 cells (immortalised human prostate epithelial cells, exhibiting IGF1 receptors) showed that GTF did not phosphorylate IGF1 receptors in these cells (N Mirsky, T Mizrahi and N Shitrit, unpublished results). Currently, we are investigating the possibility that GTF may inhibit dephosphorylation processes (as known for OrVa), which may in turn lead to increased phosphorylation of several key proteins along the insulin cellular pathway.

In summary, the present results support the hypothesis that the glucose-lowering effect of the GTF is obtained by the modulation of upstream cellular signals regulating glucose transport and nuclear activity in an insulin-like mode.

\section{Conclusions}

GTF, a dietary agent extracted and partially purified from yeast, is an insulin-mimetic and insulin-potentiating agent, exerting its effects as an anti-diabetic material in rat models exhibiting insulin deficiency. In vitro, GTF produces an insulin-like effect by phosphorylation and activation of key enzymes downstream of the insulin receptor. These results position GTF as a potential source for a novel oral medication for diabetes.

\section{Acknowledgements}

This study was supported by the Russell Berrie Foundation and D-Cure, Diabetes Care in Israel and by grants from the AM Cohen Foundation for the Advancement of Research of the Cohen Diabetic Rat and by a grant from the Ministry of Health to Sarah Weksler-Zangen. We thank Limor Chen and Linor Peér for assistance in performing some of these studies. The authors declare no conflict of interest. I. R., S. W.-Z. and N. M. proposed and designed the study. S. W.-Z. performed the study on hyp-CDs rats. N. M. performed the study on STZ rats and part of the in vitro studies. T. M. performed the in vitro studies on insulin signalling. S. W.-Z. and N. M. wrote the manuscript, and all authors approved the final version.

\section{References}

1. Malviya N, Jain S \& Malviya S (2010) Antidiabetic potential of medicinal plants. Acta Pol Pharm 67, 113-118.

2. Samad A, Shams MS, Ullah Z, et al. (2009) Status of herbal medicines in the treatment of diabetes: a review. Curr Diabetes Rev 5, 102-111.

3. Smirin P, Taler D, Abitbol G, et al. (2010) Sarcopoterium spinosum extract as an antidiabetic agent: in vitro and in vivo study. J Ethnopharmacol 129, 10-17.

4. Bjornholm M \& Zierath JR (2005) Insulin signal transduction in human skeletal muscles: identifying the defects in Type II diabetes. Biochem Soc Trans 33, 354-357.

5. Schwarz K \& Mertz W (1957) A glucose tolerance factor and its differentiation from factor 3. Arch Biochem Biophys $\mathbf{7 2}$ $515-518$

6. Holdsworth ES \& Neville E (1990) Effects of extracts of highand low-chromium brewer's yeast on metabolism of glucose by hepatocytes from rats fed on high- or low-Cr diets. $\mathrm{Br} \mathrm{J}$ Nutr 63, 623-630.

7. Mertz W \& Schwarz K (1959) Relation of glucose tolerance factor to impaired intravenous glucose tolerance of rats on stock diets. Am J Physiol 196, 614-618.

8. Tokuda M, Kashiwagi A, Wakamiya E, et al. (1987) Glucose tolerance factor stimulates 3-O-methylglucose transport into isolated rat adipocytes. Biochem Biophys Res Commun 144, 1237-1242.

9. Tuman RW \& Doisy RJ (1977) Metabolic effects of the glucose tolerance factor (GTF) in normal and genetically diabetic mice. Diabetes 26, 820-826.

10. Tuman RW, Bilbo JT \& Doisy RJ (1978) Comparison and effects of natural and synthetic glucose tolerance factor in normal and genetically diabetic mice. Diabetes 27, 49-56.

11. Mirsky N, Weiss A \& Dori Z (1980) Chromium in biological systems, I. Some observations on glucose tolerance factor in yeast. J Inorg Biochem 13, 11-21. 
12. Mirsky N, Weiss A \& Dori Z (1981) The effect of glucose tolerance factor in glucose uptake by yeast cells. J Inorg Biochem 15, 275-279.

13. Mirsky N (1993) Glucose tolerance factor reduces blood glucose and free fatty acids levels in diabetic rats. $J$ Inorg Biochem 49, 123-128.

14. Weksler-Zangen S, Yagil C, Zangen DH, et al. (2001) The newly inbred cohen diabetic rat: a nonobese normolipidemic genetic model of diet-induced type 2 diabetes expressing sex differences. Diabetes 50, 2521-2529.

15. Weksler-Zangen S, Raz I, Lenzen S, et al. (2008) Impaired glucose-stimulated insulin secretion is coupled with exocrine pancreatic lesions in the Cohen diabetic rat. Diabetes 57, 279-287.

16. Davies DM, Holdsworth ES \& Sherriff JL (1985) The isolation of glucose tolerance factors from brewer's yeast and their relationship to chromium. Biochem Med 33, 297-311.

17. Haylock SJ, Buckley PD \& Blackwell LF (1983) The relationship of chromium to the glucose tolerance factor. II. J Inorg Biochem 19, 105-117.

18. Toepfer EW, Mertz W, Polansky MM, et al. (1976) Preparation of chromium-containing material of glucose tolerance factor activity from brewer's yeast extracts and by synthesis. J Agric Food Chem 25, 162-166.

19. Mertz W (1975) Effects and metabolism of glucose tolerance factor. Nutr Rev 33, 129-135.
20. Nakhoul F, Abassi Z, Morgan M, et al. (2006) Inhibition of diabetic nephropathy in rats by an oral antidiabetic material extracted from yeast. J Am Soc Nephrol 17, S127-S131.

21. Grant AP \& McMullen JK (1982) The effect of brewers yeast containing glucose tolerance factor on the response to treatment in type 2 diabetics. A short controlled study. Ulster Med J 51, 110-114.

22. Evans GW, Roginski EE \& Mertz W (1973) Interaction of the glucose tolerance factor (GTF) with insulin. Biochem Biophys Res Commun 50, 718-722.

23. Fischer Y, Thomas J, Rose H, et al. (1992) Alanine and hyperosmolarity are responsible for the stimulation of cardiomyocyte glucose transport by samples containing a glucose tolerance factor. Life Sci 50, 1963-1972.

24. Mertz W (1993) Chromium in human nutrition: a review. J Nutr 123, 626-633.

25. Haylock SJ, Buckley PD \& Blackwell LF (1983) Separation of biologically active chromium-containing complexes from yeast extracts and other sources of glucose tolerance factor (GTF) activity. J Inorg Biochem 18, 195-211.

26. Simonoff M, Shapcott D, Alameddine S, et al. (1992) The isolation of glucose tolerance factors from brewer's yeast and their relation to chromium. Biol Trace Elem Res 32, 25-38.

27. Berdicevsky I \& Mirsky N (1994) Effects of insulin and glucose tolerance factor (GTF) on growth of Saccharomyces cerevisiae. Mycoses 37, 405-410. 